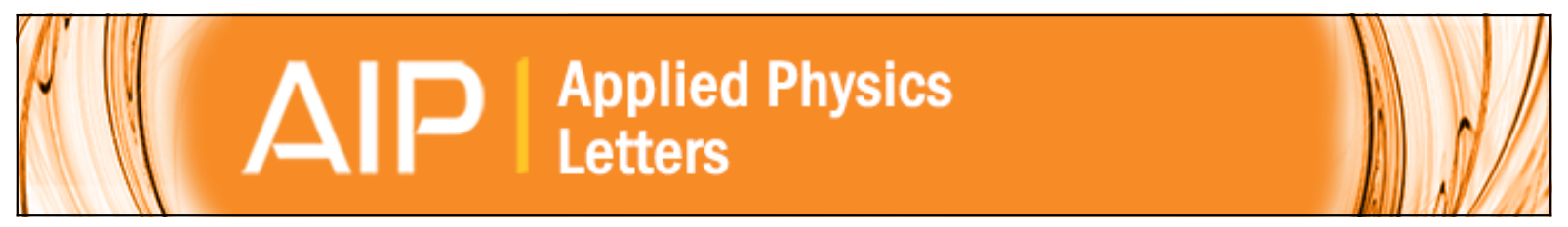

\title{
Initial stages of SiC oxidation investigated by ion scattering and angle-resolved x-ray photoelectron spectroscopies
}

C. Radtke, I. J. R. Baumvol, J. Morais, and F. C. Stedile

Citation: Applied Physics Letters 78, 3601 (2001); doi: 10.1063/1.1374518

View online: http://dx.doi.org/10.1063/1.1374518

View Table of Contents: http://scitation.aip.org/content/aip/journal/apl/78/23?ver=pdfcov

Published by the AIP Publishing

\section{Articles you may be interested in}

The initial oxidation of Al-Mg alloys: Depth-resolved quantitative analysis by angle-resolved $\mathrm{x}$-ray photoelectron spectroscopy and real-time in situ ellipsometry

J. Appl. Phys. 106, 114913 (2009); 10.1063/1.3268480

A medium energy ion scattering and x-ray photoelectron spectroscopy study of physical vapor deposited thin cerium oxide films on $\mathrm{Si}(100)$

J. Appl. Phys. 100, 044103 (2006); 10.1063/1.2234820

High resolution synchrotron radiation-based $x$-ray photoemission spectroscopy study of the Si-rich $\beta$-SiC(100)

$3 \times 2$ surface oxidation

J. Vac. Sci. Technol. B 21, 1876 (2003); 10.1116/1.1589515

Characterization of TiAIN thin film annealed under $\mathrm{O} 2$ by in situ time of flight direct recoil spectroscopy/mass spectroscopy of recoiled ions and ex situ x-ray photoelectron spectroscopy

J. Vac. Sci. Technol. A 20, 1320 (2002); 10.1116/1.1482711

Profiling nitrogen in ultrathin silicon oxynitrides with angle-resolved $\mathrm{x}$-ray photoelectron spectroscopy

J. Appl. Phys. 87, 4449 (2000); 10.1063/1.373090

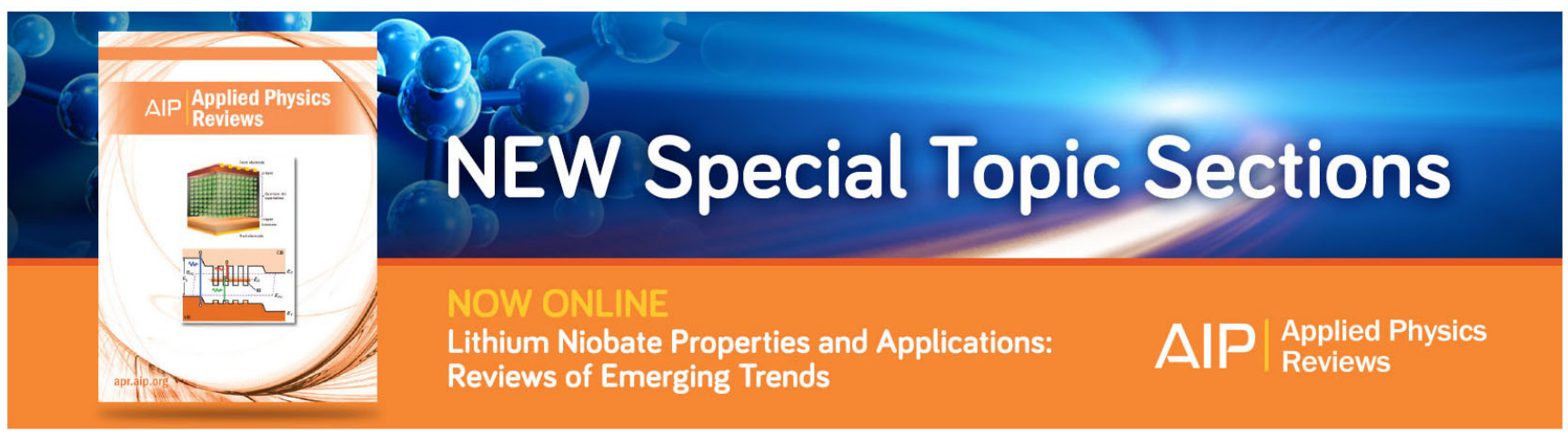




\title{
Initial stages of SiC oxidation investigated by ion scattering and angle-resolved $x$-ray photoelectron spectroscopies
}

\author{
C. Radtke, I. J. R. Baumvol, and J. Morais \\ Instituto de Física, UFRGS, Bento Gonçalves, 9500, Porto Alegre, RS, Brazil 91509-900 \\ F. C. Stedile ${ }^{\text {a) }}$ \\ Instituto de Química, UFRGS, Bento Gonçalves, 9500, Porto Alegre, RS, Brazil 91509-900
}

(Received 11 September 2000; accepted for publication 29 March 2001)

\begin{abstract}
Initial stages of oxidation of single-crystal, Si-faced silicon carbide were investigated using ion scattering and angle-resolved x-ray photoelectron spectroscopies. The very first oxidation products are shown to be silicon oxycarbides $\left(\mathrm{SiC}_{x} \mathrm{O}_{y}\right)$, while, for longer oxidation times, a mixture of $\mathrm{SiC}_{x} \mathrm{O}_{y}$ and $\mathrm{SiO}_{2}$ is formed in the near-surface region of the growing oxide film. The composition of the near-surface region of such thin films is very similar to that reported in previous investigations for the near-interface region when thicker oxides films are grown on SiC. (C) 2001 American Institute of Physics. [DOI: 10.1063/1.1374518]
\end{abstract}

Silicon carbide $(\mathrm{SiC})$ is a promising material for electronic devices that involve high-power, high-temperature, high-speed, and/or high frequency. In such harsh conditions, the most used semiconductors, $\mathrm{Si}$ and GaAs, do not present satisfactory performance due to the uncontrolled generation of intrinsic carriers. ${ }^{1,2}$ Besides its highly desirable properties, $\mathrm{SiC}$ is the only compound semiconductor that can be thermally oxidized to form $\mathrm{SiO}_{2}$, the most studied and used dielectric. This is a great advantage since the passivation of the semiconductor surface plays an important role in device fabrication. Although similarities exist between oxides thermally grown on $\mathrm{SiC}$ and on $\mathrm{Si}^{3,}{ }^{3,4}$ the former exhibits worse electrical passivation characteristics. ${ }^{5}$ The chemical structure of the oxide/ $\mathrm{SiC}$ interface is altered by the presence of carbon in the film: $\mathrm{Si}-\mathrm{C}-\mathrm{O}$ compounds, named silicon oxycarbides are formed in this interface. ${ }^{6}$ Vathulya et al. $^{7}$ correlated the carbon content in oxides grown on $\mathrm{SiC}$ to the electrical characteristics of metal-oxide-semiconductor (MOS) structures, concluding that the presence of $\mathrm{C}$ degrades the dielectric. In order for $\mathrm{SiC}$ to fulfill its potential as a large-band gap semiconductor, lower values of fixed charge densities in the oxide and interfacial trapped charge densities still must be achieved. For this reason, studies of oxidation mechanisms and composition of thermally grown oxides on $\mathrm{SiC}$ play a fundamental role in the understanding and control of the electrical characteristics of SiC-based devices.

The composition of oxides grown on $\mathrm{SiC}$ has been extensively studied by various techniques, mainly $\mathrm{x}$-ray photoelectron spectroscopy, core level photoemission spectroscopy, and secondary ion mass spectrometry. ${ }^{6,8-11}$ Önneby et $a .^{6}$ exposed $\mathrm{SiC}$ to ambient air at room temperature, yielding the formation of silicon oxycarbide species and $\mathrm{SiO}_{2}$ at long exposure times (60 days). In another work ${ }^{9}$ a C-free and rather abrupt $\mathrm{SiO}_{2} / \mathrm{SiC}$ interface was achieved when an epitaxial Si overlayer (few atomic layers) was deposited on $\mathrm{SiC}$ before oxidation. Other authors investigated thicker oxides prepared by thermal oxidation at high tem-

${ }^{a)}$ Electronic mail: stedile@if.ufrgs.br peratures of single crystal $\mathrm{SiC}(c-\mathrm{SiC})$ wafers, where depth profiling of the various species in these systems evidenced that the $\mathrm{SiO}_{2} / \mathrm{SiC}$ interface is not abrupt. ${ }^{6,10,11}$ Gradual transition between $c$ - $\mathrm{SiC}$ and amorphous $\mathrm{SiO}_{2}$ has been theoretically proposed by $a b$ initio calculations, which showed that the topology and geometry of $c$-SiC surfaces are not suitable for abrupt interfaces. ${ }^{12}$ In the present work, the first stages of oxidation of commercially available $n$-type $6 \mathrm{H}-\mathrm{SiC}(0001)$ wafers were studied in situ by means of ion scattering spectroscopy (ISS) and angle resolved x-ray photoelectron spectroscopy (ARXPS). ISS gives the elemental composition of the first atomic layer while ARXPS provides information about the chemical composition of the probed material as a function of depth. In conjunction, these two techniques constitute a powerful method to characterize the first oxidation products of $\mathrm{SiC}$.

A Si-faced $n$-type (nitrogen doped) $6 \mathrm{H}-\mathrm{SiC}$ sample cut from a wafer with resistivity $0.075 \Omega \mathrm{cm}$ supplied by Cree Inc. was used in this experiment. The sample was dipped for $30 \mathrm{~s}$ in a $5 \% \mathrm{HF}$ solution in ethanol, followed by a $30 \mathrm{~s}$ ethanol rinsing aimed at removing the native oxide. Immediately after HF etching the sample was introduced into the UHV chamber of the surface analysis facility. ISS spectra were obtained with a $\mathrm{He}^{+}$beam at $1000 \mathrm{eV}$ aiming at surface specificity, which is only achieved when low energy rare gas ions are used. ${ }^{13}$ Figure 1(a) shows the ISS spectrum from this sample, where one notices the presence of $\mathrm{Si}, \mathrm{C}, \mathrm{N}, \mathrm{O}$, and $\mathrm{F}$ at the surface. Since the sample had its (0001) face exposed, only Si should be detected. In order to remove contaminants and a possible native oxide, the wafer was heated to $850^{\circ} \mathrm{C}$ in ultrahigh vacuum (base pressure was 3 $\left.\times 10^{-10} \mathrm{mbar}\right)$ for $10 \mathrm{~min}$. Clean and stoichiometric $\beta$-SiC (100) surfaces have been obtained by a similar procedure carried out at higher temperatures. ${ }^{14}$ The ISS spectrum from the resulting surface (hereafter referred as the cleaned sample) is shown in Fig. 1(b): only Si and N (dopant species) were detected. The intensity of the $\mathrm{N}$ signal in this spectrum is comparable to that of $\mathrm{Si}$, which is a surprising observation even if one considers that the dopant concentration in $\mathrm{SiC}$ is usually two orders of magnitude higher than in $\mathrm{Si}^{2}{ }^{2} \mathrm{Such}$ a 


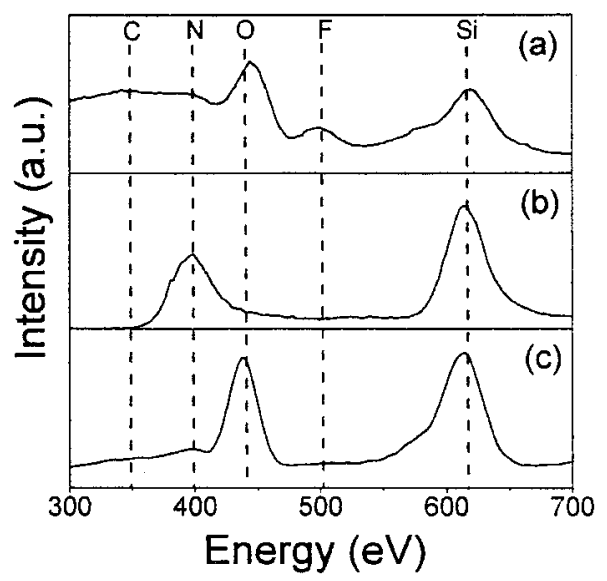

FIG. 1. ISS spectra of a $\mathrm{SiC}$ sample (a) after $\mathrm{HF}$ etching, (b) same as in (a) and then submited to heating in ultrahigh vacuum at $850{ }^{\circ} \mathrm{C}$ for $10 \mathrm{~min}$, and (c) same as in (b) and then oxidized for $8.5 \mathrm{~min}$ in a dry $\mathrm{O}_{2}$ pressure of $10^{-5}$ mbar at $850{ }^{\circ} \mathrm{C}$. Dashed lines indicate the energy position of the elements.

strong $\mathrm{N}$ signal could be due to a segregation of $\mathrm{N}$, a fact already observed after oxidation of SiC..$^{15}$ Quantification of this segregation and study of $\mathrm{N}$ chemical environment in the initial stages of $\mathrm{SiC}$ oxidation will be the subject of a forthcoming publication. The cleaned sample underwent in situ subsequent oxidation steps for total times of 5.0, 8.5, or 23.5 min in a dry $\mathrm{O}_{2}$ pressure of $10^{-5} \mathrm{mbar}$ at $850^{\circ} \mathrm{C}$. After each oxidation step ISS and ARXPS measurements were accomplished.

The ARXPS analyses were conducted using $\mathrm{Mg} \mathrm{K} \alpha$ excitation $(h \nu=1253.6 \mathrm{eV})$. Detection angle $\theta$ of the photoelectrons, with respect to the normal to the sample surface (takeoff angle), was varied from $25^{\circ}$ (bulk sensitive mode) to $70^{\circ}$ (surface sensitive mode). All spectra were fitted assuming a Shirley background. ${ }^{16}$ Lines were fitted by $80 \%$ Gaussian $+20 \%$ Lorentzian functions, setting for each line a value of full width at half maximum. The Si $2 p$ doublet was simulated by two lines with a branching ratio $2 p_{1 / 2} / 2 p_{3 / 2}$ of 0.5 (the statistical ratio) and a spin-orbit splitting of $0.6 \mathrm{eV}$. The component of the Si $2 p$ photoelectron spectrum corresponding to $\mathrm{SiC}$ was used as the binding energy reference: all other binding energies are given with respect to this one., ${ }^{6,10,11}$

Figure 2 shows Si $2 p$ and C $1 s$ regions from cleaned, 5.0 and 23.5 min oxidized $\mathrm{SiC}$ samples. One notices broadenings in both regions after oxidation which are attributed to the formation of oxygen bearing compounds. The first fitting procedure of the Si $2 p$ regions of the oxidized samples consisted of assuming two components, corresponding to $\mathrm{SiO}_{2}$ and $\mathrm{SiC}$. The $\mathrm{SiO}_{2}$ component was constrained to a binding energy $2.7 \mathrm{eV}$ higher than the $\mathrm{SiC}$ component. This procedure evidenced the presence of a third component with binding energy between those corresponding to $\mathrm{SiO}_{2}$ and $\mathrm{SiC}$. It was attributed here to silicon oxycarbide $\left(\mathrm{SiC}_{x} \mathrm{O}_{y}\right)$ compounds since $\mathrm{C}$ is less electronegative than $\mathrm{O}$. $\mathrm{C} 1 s$ regions were fitted with two components: one corresponding to $\mathrm{C}$ in $\mathrm{SiC}$ and another one lying at binding energies $1.2 \mathrm{eV}$ higher. This last component was also attributed to silicon oxycarbide since other possible C compounds, usually attributed to sample contamination, should lie at least $1.6 \mathrm{eV}$ apart from that of $\mathrm{C}$ in SiC. ${ }^{10}$ These contaminants were indeed elimi-

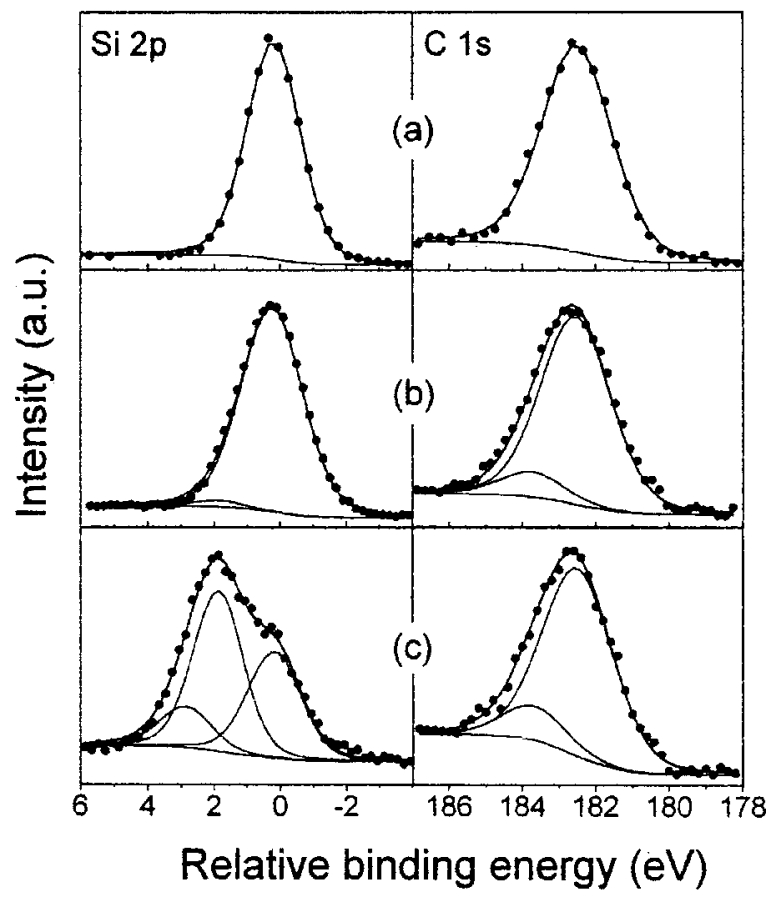

FIG. 2. Si $2 p$ (left column) and C $1 s$ (right column) regions of XPS spectra corresponding to (a) cleaned, (b) $5.0 \mathrm{~min}$ oxidized, and (c) $23.5 \mathrm{~min}$ oxidized $\mathrm{SiC}$ samples recorded with a takeoff angle of $70^{\circ}$. Points represent experimental data. Solid curves correspond to fitting components, Shirley background, and their sum. The components at binding energies 0.0 and $182.5 \mathrm{eV}$ were assigned to silicon carbide, those at 2.0 and $183.7 \mathrm{eV}$ were assigned to silicon oxycarbide, and the component at $2.7 \mathrm{eV}$ was assigned to silicon oxide.

nated after the in situ cleaning, as shown in the ISS spectrum of Fig.1(b).

Once the fitting procedure of the ARXPS was defined, the areas of the various components of $\mathrm{Si} 2 p$ regions were determined. Figure 3 shows the dependence of the relative areas of $\mathrm{SiO}_{2}$ and $\mathrm{SiC}_{x} \mathrm{O}_{y}$ components (normalized by the areas of the $\mathrm{SiC}$ component) with the cosine of the takeoff angle. The horizontal axis can be related to the analyzed

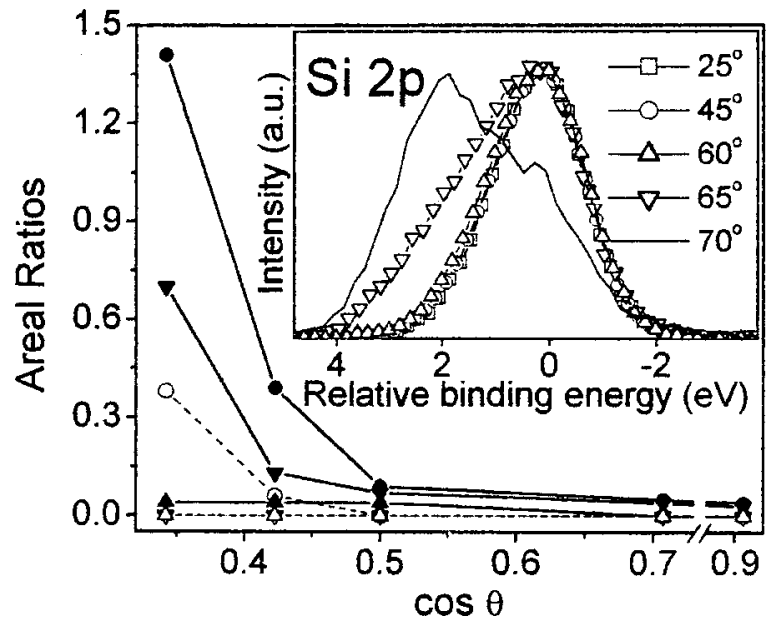

FIG. 3. Si $2 p$ components areal ratios (normalized to the $\mathrm{SiC}$ component) as a function of the cosine of the takeoff angle. Oxidation times were 5.0 (up triangles), 8.5 (down triangles), and $23.5 \mathrm{~min}$ (circles). Open symbols stand for the $\mathrm{SiO}_{2} / \mathrm{SiC}$ ratios while solid symbols stand for $\mathrm{SiC}_{x} \mathrm{O}_{y} / \mathrm{SiC}$ ratios. $\mathrm{Si}$ $2 p$ experimental regions recorded for the sample oxidized for $23.5 \mathrm{~min}$ at different takeoff angles are shoved in the inset. All regions vere normalized to the same maximum intensity after subtraction of the background. 


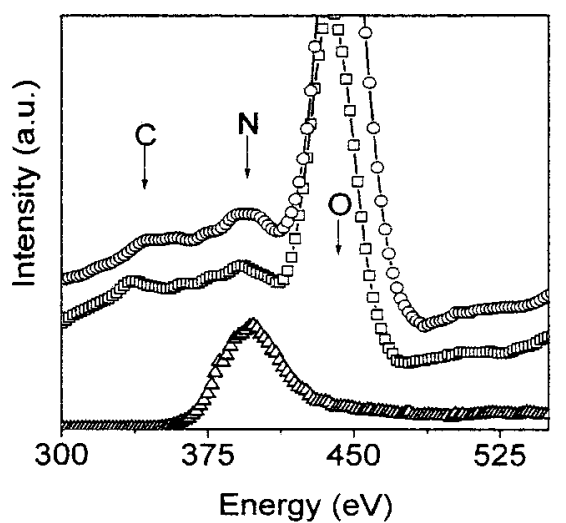

FIG. 4. ISS spectra of the cleaned (triangles), oxidized for $5.0 \mathrm{~min}$ (squares), and oxidized for $23.5 \mathrm{~min}$ (circles) $\mathrm{SiC}$ sample. Arrows indicate the energy position of the elements.

depth by $X=d \cos \theta$ where $X$ is the probed depth, $d$ is the escape depth of photoelectrons, and $\theta$ is the takeoff angle. Assuming the escape depth of Si $2 p$ photoelectrons to be 1.8 $\mathrm{nm}$-an approximate value obtained from the universal curve of electron mean free path ${ }^{17}$-one can see significant changes in the areal ratios occurring in the first nanometer below the sample surface. Greater amounts of oxygen compounds are observed as the oxidation time is increased: (i) $\mathrm{SiC}_{x} \mathrm{O}_{y}$ is detected already for the shortest oxidation time and has a pronounced increase for longer oxidation times; (ii) stoichiometric $\mathrm{SiO}_{2}$ is detected only after the longest oxidation time, and even in this case it is less abundant than silicon oxycarbide. The variation of the areal ratios of the three components in the $\mathrm{Si} 2 p$ regions as the takeoff photoelectron emission angle is varied can also be clearly seen in the inset of Fig. 3, which stands for the sample oxidized for $23.5 \mathrm{~min}$. As the takeoff angle is raised a marked asymmetry towards higher binding energy values is observed, an effect of the increasing contribution of oxidized species. Only at a $70^{\circ}$ takeoff angle the contribution due to $\mathrm{SiO}_{2}$ to the $\mathrm{Si} 2 p$ region is remarkable. The amounts of silicon oxycarbide components calculated from the $\mathrm{C} 1 s$ regions are consistent with the picture depicted in Fig. 3.

Composition of the surfaces after oxidations was accessed by ISS. Figure 1(c) shows the sample oxidized for 8.5 min: besides $\mathrm{Si}$ and some $\mathrm{N}$, already present in the cleaned sample, $\mathrm{O}$ and some $\mathrm{C}$ were also detected. In Fig. 4, one can see more clearly the presence of $\mathrm{C}, \mathrm{N}$, and $\mathrm{O}$ at the surface of $\mathrm{SiC}$ oxidized for 5.0 and $23.5 \mathrm{~min}$, corroborating the incorporation of $\mathrm{C}$ in the growing oxide films already observed by ARXPS.

Thus, the evolution of the thermal oxidation products determined by ARXPS shows that the first step of oxygen incorporation in $\mathrm{SiC}$ is the formation of silicon oxycarbides. Hornetz et al. ${ }^{10}$ have proposed that a compound formed by $\mathrm{Si}, \mathrm{C}$, and $\mathrm{O}$ is the first reaction product of a $\mathrm{Si}-\mathrm{C}$ double layer with molecular $\mathrm{O}_{2}$, consistent with the present results. For longer oxidation times, $\mathrm{Si}$ is progressively oxidized until stoichiometric $\mathrm{SiO}_{2}$ is detected in the near-surface region. As evidenced by ISS and ARXPS, silicon oxycarbides are still present in this region and therefore a complete layer of pure, stoichiometric $\mathrm{SiO}_{2}$ is not formed, indicating that even the longest oxidation time used here still represents the first stages of $\mathrm{SiC}$ oxidation. Thus, at these initial stages $\mathrm{Si}$ is bonded to a variable number of $\mathrm{C}$ and $\mathrm{O}$ atoms originating a region very similar to the previously described transition layer between $\mathrm{SiC}$ and $\mathrm{SiO}_{2}{ }^{6,10}$

Summarizing, we have investigated the first stages of $\mathrm{SiC}$ oxidation using ISS and ARXPS. The results showed that the first oxidation products are silicon oxycarbides. The amount of such compounds increases for longer oxidation times within the first nanometer below the surface. As more oxygen is supplied to the system (longer oxidation times) a mixture of silicon oxycarbides and $\mathrm{SiO}_{2}$ is detected near the surface. These initial stages of oxidation portrait the reaction environment of the dielectric/semiconductor interface during further thermal oxidation stages of $\mathrm{SiC}$.

The authors would like to thank R. P. Pezzi for performing ARXPS and ISS measurements and for helpful discussions. This work was supported in part by $\mathrm{CNPq}$ and FAPERGS.

${ }^{1}$ R. R. Siergiej, R. C. Clarke, S. Sriram, A. K. Agarwal, R. J. Bojko, A. W. Morse, V. Balakrishna, M. F. MacMillan, A. A. Burk, Jr., and C. D. Brandt, Mater. Sci. Eng., B 61-62, 9 (1999).

${ }^{2}$ H. Morkoç, S. Strite, G. B. Gao, M. E. Lin, B. Sverdlov, and M. Burns, J. Appl. Phys. 76, 1363 (1994).

${ }^{3}$ M. B. Johnson, M. E. Zvanut, and O. Richardson, J. Electron. Mater. 29, 368 (2000).

${ }^{4}$ K. McDonald, M. B. Huang, R. A. Weller, L. C. Feldman, J. R. Williams, F. C. Stedile, I. J. R. Baumvol, and C. Radtke, Appl. Phys. Lett. 76, 568 (2000).

${ }^{5}$ G. G. Jernigan, R. E. Stahlbush, M. K. Das, J. A. Cooper, Jr., and L. A. Lipkin, Appl. Phys. Lett. 74, 1448 (1999).

${ }^{6}$ C. Önneby and C. G. Pantano, J. Vac. Sci. Technol. A 15, 1597 (1997).

${ }^{7}$ V. R. Vathulya, D. N. Wang, and M. H. White, Appl. Phys. Lett. 73, 2161 (1998).

${ }^{8}$ Z. Zheng, R. E. Tressler, and K. E. Spear, J. Electrochem. Soc. 137, 854 (1990).

${ }^{9}$ F. Amy, P. Soukiassian, Y.-K. Hwu, and C. Brylinski, Appl. Phys. Lett. 75, 3360 (1999).

${ }^{10}$ B. Hornetz, H.-J. Michel, and J. Halbritter, J. Mater. Res. 9, 3088 (1994).

${ }^{11}$ H.-F. Li, S. Dimitrijev, D. Sweatman, H. B. Harrison, P. Tanner, and B. Feil, J. Appl. Phys. 86, 4316 (1999).

${ }^{12}$ R. Buczko, S. J. Pennycook, and S. T. Pantelides, Phys. Rev. Lett. 84, 943 (2000).

${ }^{13}$ D. G. Armour, in Methods of Surface Analysis, edited by J. M. Walls (Cambridge University Press, Cambridge, 1989), pp. 263-298.

${ }^{14}$ M. R. Chudoba, P. Soukiassian, C. Jaussaud, and S. Dupont, Phys. Rev. B 51, 14300 (1995).

${ }^{15}$ J. W. Palmour, R. F. Davis, H. S. Kong, S. F. Corcoran, and D. P. Griffis, J. Electrochem. Soc. 136, 502 (1989).

${ }^{16}$ D. A. Shirley, Phys. Rev. B 5, 4709 (1972).

${ }^{17}$ M. P. Seah and W. A. Dench, Surf. Interface Anal. 1, 2 (1979). 